\title{
Comparison of the central corneal thickness in diabetes mellitus patients and non diabetic individual
}

\author{
Math S. S. ${ }^{1}$, Mohta A. J. ${ }^{2}$ \\ ${ }^{1}$ Dr. Shadakshari S. Math, Associate Professor, ${ }^{2}$ Dr. AntarikshJ. Mohta, $3^{\text {rd }}$ Year Resident, both authors are affiliated in \\ the Department of Ophthalmology at Dr. D. Y. Patil Medical College Hospital \& Research Institute, DY Patil university, \\ Kolhapur, Maharashtra,India.
}

Corresponding Author: Dr. Antariksh J. Mohta, $3^{\text {rd }}$ Year Resident, Room No. 5, Boys Hostel, $5^{\text {th }}$ floor, Dr. D.Y. Patil Hospital, Kadamwadi, Kolhapur, Maharashtra, India. E-mail- antarikshmohta@gmail.com

\begin{abstract}
Background: Diabetes is associated with increase in the thickness of the cornea and also raised intraocular pressure as compared to normal healthy individuals.Diabetes causes intrinsic abnormality of the epithelial basement membrane complex \& impairs epithelial and endothelial barrier function. A few studies have been done on corneal morphological changes, corneal thickness in diabetic subjects but it is still a topic of research in Indian population. Purpose:To compare the central corneal thickness in diabetes mellitus patients and non diabetics individuals. Method: A Prospective observational study with 100 patients, 50 diabetic and 50 non-diabetics subjects was conducted from $1^{\text {st } F e b r u a r y ~} 2019$ to $30^{\text {th }}$ April 2019. All subjects underwent routine complete ophthalmological examination, central corneal thickness was measured using ultrasound pachymetery. Blood investigation like fasting blood sugars, postprandial sugars, and HbA1c levels was done among diabetics and random blood sugars were done among non diabetic subjects. Results: The mean central corneal thickness in diabetic subjects was $558.8 \pm 24.71 \mu \mathrm{m}$ as compared to non-diabetics $524.33 \pm 14.26 \mu \mathrm{m}$ and difference between the two groups was clinically significant $(\mathrm{p}<0.0001)$. The central corneal thickness was higher for diabetes with duration of $>10$ years $(567.74 \pm 5.30 \mu \mathrm{m})$ when compared to duration of diabetes $<10$ years $(550.54 \pm 13.41 \mu \mathrm{m})$ and with $\mathrm{HbA} 1 \mathrm{c}>6.5 \%$ showed statistically significant increase in mean central corneal thickness compared to HbA1c $<6.5 \%$. Conclusion: Diabetic subjects showed higher central corneal thickness as compared to nondiabetic subjects and also there was increase in central corneal thickness with increase in duration and uncontrolled diabetes. All diabetic patients need to undergo central corneal thickness assessment before any intraocular surgeries.
\end{abstract}

Keywords: Central corneal thickness, Diabetes, Pachymetery, Glycosylated haemoglobin

\section{Introduction}

The overall prevalence of diabetes in India is $7 \cdot 3 \%[1]$. In many studies, diabetes is associated with increase in the thickness of the cornea and also raised intraocular pressure as compared to normal healthy individuals $[2,3]$. There are 6 layers in the corneaepithelium, Bowman's membrane, stroma, Dua's membrane, descemet's membrane and endothelium layer.

Dysfunction of any of the above-mentioned layer can cause loss of transparency. Diabetes causes intrinsic abnormality of the epithelial basement membrane complex \& impairs epithelial and endothelial barrier function. Ultra structure abnormalities of diabetic corneal epithelial basement complexes include massive

Manuscript received: $4^{\text {th }}$ June 2019

Reviewed: $14^{\text {th }}$ June 2019

Author Corrected: $20^{\text {th }}$ June 2019

Accepted for Publication: $25^{\text {th }}$ June 2019 thickening of multilaminar basement membrane, reduce number of hemi desmosome, reduce penetration of anchoring fibrils [4,5]. These are the basal laminar disorder which are seen in diabetic patients. In diabetic patients there is compromised epithelial stromal adhesions with recurrent and persistent defects seen in epithelial layer.

Specular microscopy examination in diabetic patients shows abnormalities of corneal endothelium, such as irregularities of action fibers, polymegathism, pleomorphism, decrease in endothelial count and hexagonality with increased stromal thickness [6,7]. Intracellular accumulation of sorbitol causes osmosis leading to swelling of the endothelial cells, decline in activity of Krebs cycle which leads to reduction in ATP production thus causing endothelial pump dysfunction. 


\section{Original Research Article}

This causes change in morphology and permeability of cornea. Other ophthalmological complications associated with diabetes are low vision or blindness, dry eye, cataract, retinal blood vessel changes, macular edema, vitreous hemorrhage and diabetic retinopathy [8]. Non-ophthalmological complications due to raised blood sugar levels include stroke, cardiac failure, renal failure, myocardial infarct and also ophthalmological complications.

Aim- To compare central corneal thickness in Diabetes mellitus patients and Non diabetics individuals.

\section{Objective}

1. To compare central corneal thickness between Diabetes mellitus patients and Non diabetics.

2. To compare central corneal thickness in Diabetes mellitus patients with duration of $>10$ years and those with duration $<10$ years.

3. To compare central corneal thickness in Diabetes mellitus patients with $\mathrm{HbA1c}$ value of $>6.5 \%$ and those with $\mathrm{HbA} 1 \mathrm{c}$ value of $<6.5 \%$.

Need\&rationalization of the study- Any patients undergoing any intra-ocular surgery will have endothelial cell loss. In diabetesthe endothelial cell layer shows morphological changes so they are more prone for corneal decompensation after any intraocular surgeries. So that the status of endothelial cell layer by measuring the central corneal thickness can be known.

\section{Materials and Methods}

Type of study: This is a Prospective observational study

Duration: Duration of study was for three months from $1^{\text {st }}$ February 2019 to $30^{\text {th }}$ April 2019.

Setting of study: It is hospital-based study.

Sampling method: Consecutive sampling method adopted, all the subject meeting the criteria of inclusion were included in the present study.

\section{Sample size}

Group A- 50 Diabetes mellites patients

Group B- 50 Non diabetic individuals

\section{Inclusion criteria}

1. Patients with diabetes mellitus.

2. Age group20-70 years.

3. Non diabetic individuals.

\section{Exclusion criteria}

1. Diabetes Mellitus with hypertension, thyroid disorder and other systemic diseases.

2. Patients having glaucoma.

3. Patients having corneal pathology and any other ocular abnormalities like pterygium, entropion, trichiasis.

4. Patients who have undergone previous ocular surgeries.

5. Contact lens wearers.

6. Patients on topical and systemic steroids.

7. Patients having refractive error greater than $\pm 6 \mathrm{D}$ spherical or cylinder greater than $\pm 3 \mathrm{D}$.

8. Pregnant women.

9. Patients who are daily smokers.

10. Non-diabetic individuals with ocular or systemic disease which influences intra-ocular pressure and central corneal thickness.

Data collection procedure- In this study, comparison between the central corneal thickness in diabetes mellitus patients and controls as non-diabetic individuals was made. Also the central corneal thickness changes in relation to HbAlc levels and duration of diabetes mellitus was observed, two groups A \& B were formed.

Group A-Includes patients having diabetes mellitus (who are previously diagnosed by physician) on treatment

Group B- Includes Non diabetic individuals

Detailed history of diabetes mellitus patient will be taken regarding duration of diabetes, treatment, fasting, post prandial blood sugar levels and HbAlc will be recorded.

All the patients of Group A and Group B will undergo complete ophthalmic examination, which includes Best corrected visual acuity, slit lamp anterior segment examination, slit lamp biomicroscopy (+90D)/ indirect ophthalmoscopy for posterior segment examination.

Ultra-sound pachymetry to measure central corneal thickness. For posterior segment examination pupils will be dilated using mydriatics and slit lamp biomicroscopic/ indirect ophthalmoscopy examination will be done. Central corneal thickness and will be compared between Group A and Group B. 
Duration of diabetes from the time of diagnosis will be sub-grouped as $>10$ years and $<10$ years.

Data analysis: Was done by Unpaired $\mathrm{T}$ test
Data Analysis: Unpaired t test, Wilcoxon signed rank test, Anova test.

Ethical consideration: Ethical approval was taken.

\section{Results}

100 patients were included in the present study. 47 patients had Type 2 diabetes mellitus (all were non insulin dependent) and 3 patients had Type 1 diabetes mellitus (all were insulin dependent), and 50 patients were Non-diabetics subjects. In those 50 diabetic patients 33 were male and 17 were female. Mean age of non diabetics was $56.8 \pm 10.2$ years and that of diabetics 58.30 \pm 9.97 years ( $\mathrm{p}$ valve 0.43 ) statistically not significant. Mean age of male subjects was 59.36 $\pm 9.0 \mathrm{years}$ and that of female was $56.47 \pm 11.28$ years in diabetic group which was no statistically significant (p value 0.37 )

Table-1: Mean central corneal thickness in diabetes and non-diabetic individuals.

\begin{tabular}{|c|c|c|c|c|}
\hline Patients & n & Mean CCT $(\boldsymbol{\mu m})$ & SD & p-value \\
\hline Diabetics & 50 & 558.4 & 24.71 & \multirow{2}{*}{$\mathrm{P}<0.0001^{*}$} \\
\hline Non Diabetics & 50 & 524.33 & 14.26 & \\
\hline
\end{tabular}

Table 1 shows mean central corneal thickness which is higher $(558.8 \pm 24.71 \mu \mathrm{m})$ in diabetic patients as compared with $(524.33 \pm 14.26 \mu \mathrm{m})$ in non-diabetic,p value $<0.0001$ which is statistically significant.

Table-2: Mean central corneal thickness in diabetes with relation to duration of diabetes.

\begin{tabular}{|c|c|c|c|}
\hline Duration of diabetes & Mean CCT $\boldsymbol{\mu m}$ & SD & p-value \\
\hline \multirow{2}{*}{$<10$ years } & 550.54 & 13.49 & \multirow{2}{*}{$\mathrm{P}<0.0001^{*}$} \\
\hline
\end{tabular}

Table 2 shows mean central corneal thickness higher $(567.74 \pm 5.30 \mu \mathrm{m})$ in diabetic patients with duration greater than 10years as compared with $(550.54 \pm 13.49 \mu \mathrm{m})$ in diabetic patients with duration less than 10 years, $p$ value $<0.0001$ which is statistically significant.

Table-3: Mean central corneal thickness in diabetes with relation to glycosylated haemoglobin.

\begin{tabular}{|c|c|c|c|c|}
\hline HbA1c & $\mathbf{n}$ & Mean CCT & \pm SD & p-value \\
\hline$<6.5$ & 12 & 541.16 & 12.9 & \multirow{2}{*}{$<0.0001 *$} \\
\hline$>6.5$ & 38 & 562.54 & 11.01 & \\
\hline
\end{tabular}

Table 3 shows mean central corneal thickness higher in diabetic patients with $\mathrm{HbAlc}$ value $>6.5 \%$ as compared with diabetic patients with $\mathrm{HbA} 1 \mathrm{c}$ value $<6.5 \%$, p value $<0.0001$ which is statistically significant.

\section{Discussion}

Diabetes mellitus affects all structures of the eye. Other than diabetic retinopathy patients can also develop corneal damage such as endothelial defects, punctate epithelial keratopathy, recurrent corneal erosions and persistent epithelial defects. In diabetic individuals there is polymegathism, pleomorphism and reduction in density of corneal endothelial cells as compared to non diabetic individuals. Recent studies have shown advanced glycosylated end product act as cross linking agents to increase the covalent bond in corneal stroma and eventually its thickness. The central corneal thickness in diabetics signifies functional and morphological status of cornea. This may interfere with susceptibility to surgical stress and delayed healing after intraocular surgery like cataract surgery, refractive surgery. The present study shows mean central corneal thickness which is higher $(558.8 \pm 24.71 \mu \mathrm{m})$ in diabetic patients as compared with $(524.33 \pm 14.26 \mu \mathrm{m})$ in nondiabetic,p value $<0.0001$ which is statistically significant. In the present study it was observed that mean central corneal thickness was higher in diabetic patients with $\mathrm{HbA1c}$ value $>6.5 \%$ as compared with diabetic patients with $\mathrm{HbA1c}$ value $<6.5 \%$,p value $<$ 0.0001 which is statistically significant, also in the 
present study mean central corneal thickness was higher $(567.74 \pm 5.30 \mu \mathrm{m})$ in diabetic patients with duration greater than 10years as compared with $(550.54 \pm 13.49 \mu \mathrm{m})$ in diabetic patients with duration less than 10 years,p value $<0.0001$ which is statistically significant.

Yasemin Ozdamar; Bulent Cankaya et al found the mean CCT was significantly greater in study group (diabetics) was $564 \pm 30 \mu \mathrm{m}$ compared with control group was $538 \pm 35 \mu \mathrm{m}(P=0.001)[9]$.

Reena Sorokhaibam, Yapa Guha et al also found mean CCT was thicker in diabetic group $(574.359 \mu \mathrm{m})$ when compared to non-diabetic group $(557.76 \mu \mathrm{m})$. The difference between the 2 groups was significant $(\mathrm{p}=0.000)[10]$.

$\mathrm{Su}$ and co-workers examined the relationship of diabetes and hyperglycaemia with CCT in 3239 eyes, including 748 diabetics, and demonstrated mean CCT $6.50 \mu \mathrm{m}$ thicker in diabetics than in persons without diabetes $(\mathrm{p}<0.001)$.

Moreover, they found a correlation between corneal thickness and the higher HbA1c. These results are in accordance with the present study showing that poor diabetic compliance [11].

Dabas R, Sethi $\mathrm{S}$ et al found central corneal thickness higher in diabetics with HbA1C $>7(564.44 \pm 32.01 \mu \mathrm{m})$ in comparison to $\mathrm{HbA1C}<7 \quad(543.85 \pm 23.32 \mu \mathrm{m})$ (p < $0.009)[12]$.

Claramonte et al in a similar study showed significant relationship between diabetes and CCT. The mean CCT in diabetics in their study was $571.96 \mu$ as compared to $544.89 \mu$ in non diabetics with statistically significant difference [13].

The effect of duration of diabetes on corneal thickness was studied by Lee et al who reported the mean corneal thickness was significantly higher for diabetes of over 10 years duration $(595.9 \pm 4.2 \mu \mathrm{m})$ than for diabetes of under 10 years' duration $(582.2 \pm 3.7 \mu \mathrm{m})(\mathrm{P}<0.05)[14]$.

In the present study most of the study subjects were of type 2 diabetes mellitus and only small number of patients were of type 1 diabetes mellitus, so a study having larger sample size including type 1 diabetes mellitus patients should be done. Further studies have to be done know the relationship between central corneal thickness changes and different stages of diabetic retinopathy.

\section{Conclusion}

The present study showed that mean central corneal thickness was higher in diabetic group having duration greater than 10years and $\mathrm{HbA} 1 \mathrm{c}>6.5 \%$ as compared to non diabetic individuals. Majority of the subjects in the present study were on oral hypoglycaemics drugs diagnosed as type 2 diabetes mellitus and only 3 subjects were insulin dependent diagnosed as type 1 diabetes mellites so further studies are needed to evaluate central corneal thickness among type 1 insulindependent diabetes mellites. CCT assessment in diabetic patients should be done especially as a preoperative work up of refractive surgery, cataract surgeries, keratoplasty, glaucoma suspects etc.

This may help to prevent complications enabling the ophthalmologist to treat their disease meticulously.

\section{What this study adds to existing knowledge?}

In the present study it was observed that positive corelation between central corneal thickness changes and glycosylated haemoglobin in diabetes mellitus patients which adds to existing knowledge.

\section{Funding: Nil, Conflict of interest: Nil Permission from IRB: Yes}

\section{References}

1. Anjana RM, Deepa M, Pradeepa R, Mahanta J, Narain K, Das HK, et al. Prevalence of diabetes and prediabetes in 15 states of India: results from the ICMR-INDIAB population-based cross-sectional study. Lancet Diabetes Endocrinol. 2017;5(8):585-596. DOI: 10.1016/S2213-8587(17)30174-2. Epub 2017 Jun 7.

2. Becker B. Diabetes mellitus and primary open-angle glaucoma. The XXVII Edward Jackson Memorial Lecture. Am J Ophthalmol. 1971; 71(1 Pt 1): 1-16. DOI:10. 1016/ 0002-9394(71)91088-9

3. Ellis JD, Evans JM, Ruta DA, Baines PS, Leese G, MacDonald TM, et al. Glaucoma incidence in an unselected cohort of diabetic patients: is diabetes mellitus a risk factor for glaucoma? DARTS/MEMO collaboration. Diabetes Audit and Research in Tayside Study. Medicines Monitoring Unit. Br J Ophthalmol 2000; 84(11):1218-24. DOI:http://dx.doi.org/ 10.1136/ bjo.84. 11.1218

4. Schultz RO, Matsuda M, Yee RW, Edelhauser HF, Schultz KJ. Corneal endothelial changes in type I and type II diabetes mellitus. Am J Ophthalmol. 1984;98(4): 401-10. DOI:10.1016/ 0002-9394 (84) 90120-x 


\section{Original Research Article}

5. Keoleian GM, Pach JM, Hodge DO, Trocme SD, Bourne WM. Structural and functional studies of the corneal endothelium in diabetes mellitus. Am J Ophthalmol. 1992; 113(1):64-70. DOI:10.1016/s00029394 (14)75755-1

6. Lee JS, Oum BS, Choi HY, Lee JE, Cho BM. Differences in corneal thickness and corneal endothelium related to duration in diabetes. Eye (Lond). 2006;20(3):315-8.

7. Inoue $\mathrm{K}$, Kato S, Inoue $\mathrm{Y}$, Amano S, Oshika T. The corneal endothelium and thickness in type II diabetes mellitus. Jpn J Ophthalmol. 2002;46(1):65-9.

8. Fong DS, Aiello LP, Ferris FL 3rd,Klein R.Diabetic retinopathy. Diab Care. 2004;27(10):2540-53. DOI:10. 2337/diacare.27.10.2540

9. Ozdamar Y, Cankaya B, Ozalp S, Acaroglu G, Karakaya J,Özkan SS. Is there a correlation between diabetes mellitus and central corneal thickness? J Glaucoma. 2010; 19(9): 613-6. DOI: 10.1097/IJG. 0b013e 3181ca7c62.
10. Sorokhaibam R, Guha Y, Usharani L, Kaye T, Kamei GL, Meetei Y. Study on correlation between Diabetes mellitus and Central corneal thickness. IOSR J Dent Med Sci (IOSR-JDMS). 2015;14(11) 89-92.

11. Su DH, Wong TY, Wong WL, Saw SM, Tan DT, Shen SY, et al. Diabetes, hyperglycemia, and central corneal thickness: the Singapore Malay Eye Study. Ophthalmol. 2008;115(6):964-968.e1. Epub 2007 Oct 26. DOI:10.1016/j.ophtha.2007.08.021

12. Dabas R, Sethi S, Garg M, Aggarwal R, Lamba S, Bhattacharjee A, Tandon A. Central Corneal Thickness (CCT) in Diabetic Subjects and its Correlation with Disease Duration and Severity. Ann Int Med Den Res 2017; 3(5):04-06. DOI: 10.21276/aimdr.2017.3.5.OT2

13. Claramonte PJ, Ruiz-Moreno JM, Sánchez-Pérez SI, et al. [Variation of central corneal thickness in diabetic patients as detected by ultrasonic pachymetry]. Arch Soc Esp Oftalmol. 2006; 81(9):523-6.

14. Lee JS, Oum BS, Choi HY, Lee JE, Cho BM. Differences in corneal thickness and corneal endothelium related to duration in diabetes. Eye (Lond). 2006;20(3):315-8.DOI:10.1038/sj.eye.6701868.

\section{How to cite this article?}

Math S. S, Mohta A. J. Comparison of the central corneal thickness in diabetes mellitus patients and non diabetic individual. Trop J Ophthalmol Otolaryngol.2019;4(3):207-211.doi:10.17511/jooo.2019.i03.05 